\title{
Karl Polanyi, pensamiento económico disidente y propuesta teórica
}

\author{
Pedro Huerta M. \\ Universidad Academia de Humanismo Cristiano, Santiago, Chile. \\ Email:phuerta66@gmail.com
}

\begin{abstract}
Resumen: El presente artículo busca revisitar el pensamiento económico de Karl Polanyi, respecto de sus aportaciones metodológicas para comprender la dimensión económica de la realidad social, esclarecida de reduccionismos economicistas. Intento presentar el pensamiento del autor como aportación critica al análisis económico de la realidad social, develando las etapas de su pensamiento y los principios fundantes de una aproximación compleja al campo de los hechos que llamamos económicos.
\end{abstract} nomía.

Palabras Claves: Karl Polanyi, instituciones, modos de integración, eco-

\section{Karl Polanyi: dissident economic thought, theoretical proposal}

\begin{abstract}
This paper seeks to revisit the methodological aspects of the economic contributions of Karl Polanyi in order to understand the economic dimension of the social reality without economistic reductionism. I attempt to present the author's thinking as critical contribution to the economic analysis of social reality, revealing the stages of his thought and the founding principles of a complex approach to the field of events that we categorize as economic.
\end{abstract}

Keywords: Karl Polanyi, institutions, modes of integration economy.

\section{Karl Polanyi, pensamento econômico dissidente e proposta teórica}

Resumo: O presente artigo procura revisitar o pensamento econômico de Karl Polanyi, a respeito de suas contribuições metodológicas para compreender a dimensão econômica da realidade social, esclarecida de reducionismos economicistas. Tento apresentar o pensamento do autor como aporte critico ao análise econômico da realidade social, desvelando as etapas de seu pensamento e os princípios fundantes de una aproximação complexa ao campo dos fatos que chamamos econômicos. economia.

Palavras-Chaves: Karl Polanyi, Instituições, modos de integração,

$$
* * *
$$


En cualquier caso, las formas de integración no representan "etapas” de desarrollo. No implican ningún orden temporal. Las distintas formas subordinadas pueden presentarse al mismo tiempo que las dominantes, que pueden repetirse después de un eclipse temporal.

Karl Polanyi. La economía como proceso institucionalizado, p.167

\section{Antecedentes previos}

Para comprender el pensamiento del economista húngaro respecto del campo de los hechos económicos, es precisoinsertar su reflexión en el marco de una crítica más general a la "utopía económica" "puesta en marcha a principios del siglo XVIII por los representantes de la economía política escocesa, que se impuso en los países occidentales a lo largo del siglo XIX, y se autonomizó de la sociedad para convertirse en mercado autorregulado y, a la vez, para invadir desde el centro toda la vida social”( Alvarez-Uria,2014:18).

Cabe reconocer quelas practicas económicas de producción, distribución y consumo así comolos factores que se asocian a ella, tales como riquezay estatus social, estuvieron presentes en la vida social desdelas primeras expresiones complejas de organización social, como ha quedado demostradoen la antropología económica, en obras como la de Marshall Sahlins "La opulencia de la edad de piedra". Lo novedosodel comportamiento económico de las sociedades modernas y que será la base de la configuración de la economía como ciencia moderna formal, es la centralidad que comienzan a tener en lasprácticas económicas la búsqueda incesante de la ganancia como finesúltimosde lasacciones económicas Esto será para Polanyi la matriz central desde donde se articulará una definición formal del campo de los hechos económicos que, a juicio del mismo autor, "descoyuntó las viejas instituciones sociales heredadas, y sirvió de base durante la primera mitad del siglo XX a los Estados totalitarios promovidos por el fascismo y el nacional socialismo” (Alvarez-Uria,2014:18).

El desarrollo de la economía convencional fue, en efecto, posible a partir del desarrollo de las sociedades modernas durante los siglos XVIII, y XIX, sobre la base de un crecimiento material sostenido en ciertas regiones del mundo occidental, que permitió impulsar los ideales de la "la sociedadde la abundancia”, y engendraría unade las ideas más influyentes del mundo occidental, la idea de“progreso”.

Este progreso en el plano económico, sólo podía ser posible en el marco de la libertad mercantil, lo que paulatinamente fue posicionando el concepto rector de la práctica política y económica de las sociedades durante el siglo XVIII y XIX, el liberalismo económico. En ese marco histórico surgió la "Economía Política" desarrollada por el pensador calvinistas escoces Adam Smith y, posteriormente, por el empresario y economista 
inglés David Ricardo. La economía política clásica nació vinculada a la necesidad de elaborar un lenguaje conceptual que dieran cuenta de las transformaciones que acontecían en la estructura productiva y social de algunos sectores de Inglaterra, cuestión que venía dándose desde el siglo XVII principalmente en los Países Bajos, con el particular desarrollo de una economía productivistas, con prácticas “capitalistas” de gestión.

Los supuestos que estaban a la base de estas teorizaciones de la ciencia económica convencional, erala búsqueda de la riqueza,como norte de todas las prácticas económicas, a eso se le llamó "progreso” en el siglo XIX o “desarrollo” a mediados del XX. Lo anterior, consolidóla elaboración deun concepto de economía que diera cuenta de lo que estaba aconteciendo y debía acontecer, así también,las maneras deimpulsarlo. Así fue muy resumidamente, como apareció el análisis formal de la economía:El hombre constató la insuficiencia de media (la escasez), frente a esto, actuó racionalmente maximizando, economizando y aumentando los medios para satisfacer esos fines ilimitados, es decir una elaboración abstracta y universal del Homos Economicusmoderno.

El enunciado anterior fundó dos premisas básicas de la economía moderna, a saber el ahorro y la inversión. El origen de la acción económica moderna, en este enfoque, se centra en la lógica de la acción racional aplicada a todos los medios y fines que abarca la casi infinita variedad de intereses humanos. Ello fue un asunto tratado por la teoría de la modernización, al establecer los momentos del despegue -take off- de las economías tradicionales regidas a través de un parámetro de inversión racional del capital, es decir, entendiendo el capital como agente central del despegue de la economía hacia el desarrollo autonomizado de las relaciones sociales y culturales de la producción, distribución y el consumo.

Bajosestossupuestos de la economía convencional, el hombre actúa perse, maximizando y racionalizando, ya que se encuentra sometido a la escasez. Ello otorga a la actividad económica un carácter universal, donde estas prácticas de la alta economía, para no hacer alusión a la vida cotidiana en su desenvolvimiento real, son en esencia las que determinan la configuración del concepto de "lo económico" desde el punto de vista convencional.

En el marco de análisis convencional de la economía cómopodemos entender a las comunidades pastoriles de Cerdeña y a muchas otras más, quienes organizaban periódicamente fiestas colectivas en las que despilfarraban gran parte de su excedente a expensas de su capacidad de ahorrar e invertir. En otras palabras, como podemos autonomizar la practica económica de las demás esferas de la sociedad que le dan su posibilidad de funcionamiento.

Sin duda esta elección puede analizarse microeconómicamente en términos de las preferencias individuales relacionadas con el bienestar "no podemos decir que es mejor que los pobres coman a veces tanta carne como puedan en lugar de no comer nunca suficiente carne. Tampoco expli- 
caría un análisis de la elección racional-individual la diferencia entre estas pautas de consumo y las que están manifestando ahora en el hinterland sardo a medida que va penetrando en el la opulenta sociedad de consumo" (Hobswam, 1998:121).

Si nos guiamos por el modelo convencional formal de la economía y las ciencias sociales tradicionales del desarrollo,el hombre en todas las circunstancias maximiza y racionaliza, por tanto, el modelo sería aplicable a todas las circunstancias del devenir social. Estas premisas, fundarían un análisis estático de la realidad económica a partir de un método deductivo y generalizable a todas las sociedades.

Al respecto, es que queremos revisitar el pensamiento económico de Karl Polanyi como aportación metodológica a las ciencias sociales,fuera de los convencionalismos reduccionistas de cierta economía y sociología llana a las categorizaciones abstractas y universales desprovistas de un análisis integral de lo económico en su desenvolvimiento histórico.

\section{La formación de su pensamiento disidente}

Las aportaciones intelectuales de Karl Polanyi comienzan a desarrollarse como articulista de la revista OesterreichischeVolkswirt (El economista austriaco). En esos años,Polanyi se vio enfrentado al enfoque de análisis económico Vienes, peyorativamente señalado como "escuela austriaca” por el historicismo económico alemán preponderante en la época, lo que se conoce actualmente en el campo de la ciencia económica como enfoque marginalista.

Elideario de los economistas de Viena entre ellos Friederich Von Hayek, Gaetano Pirou, era la defensa a la libre empresa, el mercado libre y autorregulado por los mecanismos de oferta y demanda, la propiedad privada como expresiones del progreso económico y social. Ello los hacía parte de la matriz analítica del pensamiento económico liberal. En términos epistemológicos adscribían a un esquema de método matemático basado en el concepto de utilidad marginal y de racionalidad maximizadora del sujeto económico.

La Unión Soviética en el contexto de los años 20 orientó su economía desde una perspectiva planificada, lo que se conoce como planes quinquenales, duramente criticado por los economistas vieneses. Esta crítica fue canalizada principalmente por Friederich Von Hayek, Gaetano Pirou, quienes negaron la eficiencia y el progreso del modelo soviético por la vía de la planificación. Veían en esas características la imposibilidad misma de su supervivencia, en tanto contradecía las leyes naturales del libre intercambio.

Respecto de este análisis, Polanyi manifestó sus discrepanciasque se expresaban en la eficiencia del progreso de las economías de los países 
atrasados de Europa Central, por la vía de la planificación, con acento en la demanda social comoregla general del mismo proceso. Lo anterior, se tradujo en el inicio de las hostilidades teóricas y metodológicas frente al liberalismo racionalista dominante en la ciencia económica.

Desde entonces Polanyi, fue un economista disidente sin negar el aporte académico de estos enfoques. Constató las limitaciones de estos en muchos campos de la realidad y, específicamente, cuando se basaban en un esquema universal de comportamiento económico, cuyas instituciones preponderantes eran las economías de mercado formadora de precios, vistas como un orden natural y espontáneo ${ }^{1}$.

Una vez radicado en Inglaterra y cuando apenas se vislumbraba la reactivación económica de la depresión de los años 30, “Polanyi comenzó a enseñar Historia Económica en la , un programa de educación para adultos de las Universidades de y "(Godelier 1976:10). Sus clases se orientarona la historia económica inglesa, que constituía el paradigma de las economías de mercado y las transformaciones productivas y sociales que ello implicaba en la sociedad. Otra de las aristas que abordó, fue la explicación de las causas del ascenso de los fascismos, la crisis económica del 29 y las guerras mundiales. Estas clases constituyeron un material clave en la elaboración de uno de sus trabajos más conocidos e influyentes "La gran transformación: Los orígenes económicos y sociales de nuestro tiempo”publicado en 1944 en Estados Unidos.

En “La gran transformación” expresó sus conclusiones respecto al fracaso de lo que consideraba la utopía del liberalismo económico, la pretensión de edificar una sociedad a partir de un mercado autorregulado (Polanyi, 2003: 26). Polanyi visualizó que los dispositivos más elementales capaces de generar la sociedad habían quedado heridos de muerte. La historia del siglo XX se había acelerado ya demasiado para que la sociedad pudiera seguir sin sobresaltos. A decir verdad -sentencia Polanyi- "la sociedad se habría visto aniquilada, si no fuese porque los contra movimientos de defensa que amortiguaron la acción de ese mecanismo auto destructor" (Polanyi, 2003:36), contra movimientos que, finalmente, acabarían por desembocar, por una parte, en el socialismo, y por otra, en el fascismo y el nacionalsocialismo. En adelante, para Polanyi la historia, es la historia de la autodefensa de la sociedad frente a la utopía del mercado autorregulado, la historia del proteccionismo frente a la idea de mercantilización de todas las cosas.

“La civilización del siglo XIX no fue destruida por un ataque exterior o interior de los bárbaros; su vitalidad no se vio minada ni por las devastaciones de la Primera Guerra mundial, ni por la rebelión de un proletariado socialista o de una pequeña burguesía fascista. Su fracaso no fue consecuencia de supuestas leyes de la economía, tales como la baja tendencial de la tasa de ganancias, la del subconsumo o la de la super-producción. Su desintegración fue más bien el resultado de un conjunto de causas muy diferentes: las medidas adopta- 
das por la sociedad para no verse aniquilada por la acción del mercado autorregulado.” (Polanyi, 2003: 393)

El análisis histórico de “la gran transformación” se inicia con la compresión de las reacciones sociales que se dieron en el contexto de la Inglaterra de finales del siglo XVIII, a la mercantilización de las esferas de la vida social que hasta ese momento habían quedado al margen del comercio, como la tierra o la fuerza de trabajo (Rendules, 2004). Otra de las conclusiones que se desprenden de este trabajo, entre muchas, es la reorientación que irá adquiriendo el Estado en el campo de la economía y la planificación económica que, afianzadas por el keynesianismo, jugaría un rol clave en la edad dorada del capitalismo, utilizando el término de Eric Hobsbawm para caracterizar el periodo de 1947 a 1973. En esos momentos, Polanyi se sintió atraído por los socialistas británicos y simpatizó con algunas de las facciones más utopistas que elaboraron programas de reconstrucción de las sociedades de posguerra.

En 1947 Polanyi fue nombrado profesor de historia económica general en la Universidad de Columbia en Nueva York. En esta etapa de su carrera académica profundizó sus ideas que venía desarrollando desde "la gran transformación”respecto del campo del análisis económico convencional. El autor revitalizó su crítica a la economía de mercado autorregulado, publicando un pequeño trabajo bajo el nombre de Obsolete market mentality (Godelier, 1976:10), luego de ello, desarrolló un programa de investigación interdisciplinario con antropólogos, historiadores, sociólogos y economistas encaminado a establecer los orígenes de las instituciones económicas, que decantaría posteriormente en la publicación de la obra "Mercado y comercio en los imperios antiguos”de 1957 considerada la obra mayor profundización de sus posturas teóricas.

En esta etapa sus trabajos se orientaron en tres direcciones. "Primero, la crítica a lo que denomino teoría económica formal, segundo la configuración de una tipología de prácticas de integración económica, y tercero, el origen y la historia de las instituciones económicas, como el comercio administrado, el mercado libre y los diversos usos de la moneda lo que daría paso a su concepción de la economía como una actividad institucionalizada” (Godelier 1976:11).

\section{De la disidencia a la teoría sustantivista}

A continuación, exploraré el modo que establece Polanyi para fundar un análisis de la dimensión económica de la realidad centrándome en un artículo publicado en el periodo de su estadía en Norteamérica, donde consolidó empíricamente sus posturas teóricas que venía desarrollando desde “La gran transformación”.

“La economía como actividad institucionalizada”,es un artículo publicado en 1957 por la Universidad de Columbia en Trade and market in the 
early empires, publicado en español en 1976 por editorial Labor. En el caso del presente análisis trabajaré con la publicación del artículo compilado por Maurice Godelier en “Antropología y Economía” de Editorial Anagrama de 1976. En este artículo se sienta la base científica de su propuesta analítica.

En términos generales, el propósito de este artículo es instalar una concepción del término económico que permita producir los conceptos que requieren las ciencias sociales para la investigación y el análisis de los sistemas económicos empíricos del pasado y del presente(Polanyi 1983), que debe ser entendida como el punto de partida de su modo de abordar el análisis del campo de los hechos económicos, de este se desprenden aportaciones de valides para el trabajo de economistas, antropólogos, sociólogos e historiadores.

\section{La configuración del enfoque sustantivista}

El modo de abordar el análisis económico en Polanyi, parte de una ampliación del concepto de economía que se expresa en la revisión y análisis del término “económico”. El autor somete a análisis el significado del término “económico” en dos visiones bien marcadas. La primera, la designa con el nombre de definición real o sustantiva que es el supuesto elemental de su modelo de análisis, “aquella que deriva de la dependencia del hombre, para su subsistencia, de la naturaleza y de sus semejantes. Se refiere al intercambio con el medio ambiente natural y social, en la medida en que este intercambio tiene como resultado proporcionarle medios para su necesaria satisfacción material” (Polanyi, 1976: 155).

La segunda, que llamó significado formal de la economía, refiere según Polanyi aquella que “deriva del carácter lógico de la relación mediosfines, tal como aparece en la palabra económico (barato) o economizar (ahorrar). Se refiere a la concreta situación de elegir, especialmente a la elección entre distintos uso de los medios que provoca la insuficiencia de estos medios. Si denominamos lógica de la acción racional a la elección que determina la elección de los medios, podemos denominar a esta variante de la lógica con el término improvisado de economía formal” (Ibíd.).

El autor establece que ambas definiciones sobre el término económico no expresan una raíz epistemológica común, más bien éstas fundarían modos diferentes de abordar el análisis de la realidad económica. No obstante, Polanyi visualiza que dichas definiciones se dan en la realidad, y que, por tanto, no son necesariamente excluyentes, sin embargo, un análisis meramente formal expresa reduccionismo en muchos campos del análisis económico.La definición Formal de la economía para este economista, parte de un modelo analítico centrado en la escasez, expresado en la insuficiencia de medios para satisfacer las necesidades que poseen un carácter ilimitado, lo que establece, a su vez, la definición más convencional que conocemos de economía. Siguiendo el argumento de Polanyi, el hombre constata la insuficiencia de medios (la escasez), en consideración, éste actúa racional- 
mente maximizando, economizando y aumentando los medios para satisfacer esos fines ilimitados. El enunciado anterior, funda dos premisas básicas de las economías modernas, a saber: ahorro e inversión. En este enfoque entonces, el origen de la acción económica se centra en la lógica de la acción racional del sujeto aplicado a todos los medios y fines que abarca la casi infinita variedad de intereses humanos. En tal universalismo, radica una de las críticas centrales de Polanyi respecto del análisis formal de la economía.

"La utilización del significado formal de la economía denota que el sistema económico es una secuencia de actos para ahorrar, es decir, de elecciones inducidas por situación de escasez. Mientras que las reglas que determinan tales actos son universales, en la medida en que estas normas pueden aplicarse en concreto a un sistema económico depende de si tal sistema económico consiste, de hecho, en una secuencia de tales actos. Para producir resultados cuantitativos, los movimientos de localización y de apropiación, de que consta el proceso económico, deben presentarse aquí como funciones de las acciones sociales con respecto a los medios insuficientes y orientados por los precios resultantes. Tal situación solo se consigue en un sistema de mercado” (Polanyi 1976:159)

El método analítico de la definición formal de la economía procede para Polanyi de circunstancias históricas delimitadas y singulares; la configuración de economías de mercado formadores de precios a partir del siglo XIX, en Europa y Norteamérica, inspiradas en el ideario del liberalismo económico y la lógica de los mercados autorregulados. Polanyi no descarta de plano que, en los contextos citados no sea pertinente desplegar una teoría económica basada en una concepción de la acción racional de los agentes, más bien, visualiza las limitaciones de esta perspectiva, y un cierto sesgo apologético de la misma, que se manifiesta en la pretensión de entender estas prácticas como universales.

Para este economista, las condiciones del mercado autorregulado constituyen una excepcionalidad histórica, y no un esquema universal del comportamiento económico, tampoco un modelo que exprese toda la complejidad del campo de las prácticas económicas. A decir verdad, Polanyi establece las limitaciones de este modelo analítico, resididas, en la pretensión de categorizar un sujeto económico universal dotándolo con características modernas y racionales a priori, sin condescendencia empírica, a su vez, elaboradas a partir categorías abstractas, a-histórico, con ciertos rasgos etno y eurocéntricos:

“La relación entre la economía formal y el sistema económico humano es, en efecto, contingente. Fuera del sistema de precios formado por el mercado, el análisis económico pierde la mayor parte de su relevancia como método de investigación del sistema económico. Un sistema económico de planificación central que se basa en el precio no creado por el mercado, constituye un ejemplo bien conocido" (Polanyi 1976:159) 
La base de la argumentación critica que establece Polanyi en relación al análisis formal, lo deriva de investigaciones antropológicas e históricas en las cuales funda un modo de abordar la economía a partir del estudio empírico del comportamiento y de las prácticas económicas en el largo plazo, amalgamadas con otras esferas de la realidad que ha adquirido el nombre de enfoque sustantivista.

En efecto, se desprende una crítica a posiciones que el autor denomina como empiristas abstractas, construidas sobre la base de categorías de análisis vacías respecto de su contenido histórico y antropológico, es decir, una serie de construcciones teóricas de carácter metafórico basadas en abstracciones universales. En este plano crítico la obra de Talcott Parsons que suponía al mercado como la institución económica prototípica y la lógica de la acción racional de intercambios mercantiles como la base de una teoría universal de las acciones humanas.

Para los efectos de ampliar los márgenes del análisis económico formal, el autor propuso una definición que permitiese abarcar variadas formas posibles de economías, desprovista de cualquier prejuicio en cuanto a cuales formas eran posibles y cuáles no. A tal definición de la economía la denominó como real o sustantiva, una visión de la economía entendida no sólo como pretensión de economización racional universal per se, sino, como las múltiples formas que adquiere la búsqueda del sustento humano, en relación con el medio natural y social, cuyo propósito es posible por los dispositivos culturales y sociales entendidos como instituciones. En esta perspectiva, el estudio de la economía debía ser estudiado en las acciones específicas que adquiere el proceso económico en las relaciones sociales, y así mismo, desde un enfoque histórico. Estas acciones empíricas de carácter histórico y antropológico, finalmente, expresan la substancia de las categorías elaboradas en el modo de análisis Polanyiano de la economía.

\section{El enfoque sustantivista}

El modo analítico del autor se sustenta en la definición real o sustantiva de la economía, que surge del proceso institucionalizado de interacción entre el hombre y el medio, dotándole a esta interacción de manera continuada de los medios materiales para satisfacer sus necesidades (Polanyi 1976:159). A partir de esta definición, Polanyi elabora un modo de análisis económico como proceso en el cual se institucionalizan las prácticas económicas, siendo estos procesos la manifestación de movimientos económicos de transacción y disposición en el modo en que estos se institucionalizan en la sociedad.

Respecto del concepto de “proceso” económico, Polanyi lo ve como movimiento, es decir, como movimientos que se expresan en "cambios de localización o bien cambios de apropiación o bien ambos” (Polanyi 1976:159).De esta manera, el proceso económico puede manifestarse en dos tipos de movimientos, por una parte, el de localización que incluye la pro- 
ducción y el transporte para “el cual el traslado espacial del objeto es igualmente esencial” (Ibíd.) Por su parte, el movimiento de apropiación que “designa generalmente la circulación de bienes como su administración” (Ibíd.). En el primer caso, el "movimiento de apropiación” es el resultado de una transacción; en el segundo de disposición. Por transacción, Polanyi entiende "un movimiento de apropiación que ocurre entre manos” (Ibíd.), el termino mano se utiliza en el autor, para denominar los cargos y los organismos públicos, así como las personas o firmas privadas, siendo la diferencia entre ellas una cuestión de organización interna. Por disposición, entiende las fuerzas de la costumbre o de la ley a las cuales se le atribuye efectos concretos de apropiación:

“Las actividades sociales en la medida que forman parte del proceso, pueden denominarse económicas; las instituciones se denominan así en la medida en que contienen una concentración de tales actividades: todos los componentes que forman parte del proceso pueden considerarse elementos económicos” (Polanyi, 1976:160).

La cita anterior es decidora en dos planos, primero, fundar un modo de análisis económico más allá del mero reduccionismo economicista, y segundo, el rol que juegan las instituciones en el proceso económico, entendidas como construcciones y disposiciones sociales donde lo económico adquiere valides. Ésta, se manifiestan en dispositivos culturales y sociales que dan unidad y estabilidad al proceso económico en el tiempo, es decir en la manera en que los procesos entendidos como movimientos económicos de apropiación y disposición se institucionalizan. El modo de institucionalización del proceso económico, entonces, se produce a partir de dos categorías que el autor expone con bastante claridad en el siguiente párrafo:

“La institucionalización del proceso económico dota al proceso de unidad y estabilidad crea una estructura con una función determinada en la sociedad; traslada el lugar del proceso en la sociedad añadiendo de este modo significación a su historia; centra el interés en los valores, los motivos y la política. Unidad y estabilidad, estructura y función,historia y política deletrean de forma operacional el contenido de nuestra afirmación de que el sistema económico humano es un proceso institucionalizado” (Polanyi, 1976:161).

Siguiendo los planteamientos del autor, la puesta en práctica de la institucionalización de las actividades económicas, entendidas como procesos de “movimiento de transacción” $y$ “disposición”, se generan a partir de la unidad, en tanto estructuración de estos procesos en el tiempo (historia) ,y estabilidad, como la función de estas prácticas en la contingencia (política). A partir de ello, se desprende que para Polanyi la actividad económica humana está incrustada y amalgamada en instituciones culturales y sociales.

El modo del autor para abordar la economía, entonces, va más allá de una simple apendización de lo social, lo político y lo cultural en el proceso 
económico, en tanto lo económico es un hecho total, donde las esferas de la realidad social son dispositivos posibilitadores de las prácticas económicas, en esencia constitutivas del mismo proceso, al decir de Polanyi:

"La economía humana, pues, esta incrustada y enredada en instituciones económicas y no económicas. La inclusión de lo no económico es vital. Pues la religión o el gobierno pueden ser tan importantes para la estructura y el funcionamiento de la economía como las instituciones monetarias o la disponibilidad de herramientas y maquinas que aligeran el trabajo de la mano de obra” (Polanyi, 1976:161).

\section{Los modos de integración de integración económica. Reciprocidad, redistribución e intercambio}

La perspectiva institucionalista del autor, se funda en el estudio de la economía como un proceso no estático, es decir, como movimientos, que dan paso a las diversas formas en las cuales se instituye lo económico en las sociedades y a lo largo del tiempo. Polanyi establece que la configuración de economías empíricas se produce por medio de la interdependencia y recurrencia, es decir, en la combinación de “formas de integración”, las que se presentan coetáneamente, en diferentes niveles y sectores de la economía que, a lo largo del devenir de la historia humana, se manifiestan sin imposición de una forma de integración por sobre otras ${ }^{2}$.

"Empíricamente encontramos que las principales pautas son la reciprocidad, la redistribución y el intercambio. La reciprocidad denota movimientos entre puntos correlativos de agrupamiento simétricos; la redistribución designa movimientos de apropiación hacia un centro y luego hacia el exterior; el intercambio hace referencia aquí a movimientos y viceversa en un sentido y en el contrario que tiene lugar como entre manos en el sistema de mercado (Polanyi, 1976:162).

Siguiendo el esquema analítico del autor, estas formas de integración no son agregados de comportamiento interpersonales ni individuales, más bien, sus posibilidades dependen de determinados dispositivos institucionales como las organizaciones asimétricas centralizadas que operan en las prácticas de redistribución, o los sistemas de organización simétricos que posibilitan las prácticas de reciprocidad. De manera que las posibilidades de desarrollo de estas formas de integración dependen, en esencia, de apoyos institucionales concretos:

"En la esfera económica es tan frecuente que el comportamiento interpersonal no tenga los esperados efectos en ausencia de unas concretas precondiciones institucionalizadas. Solo en un medio ambiente simétricamente organizado producirá el comportamiento reciproco instituciones económicas de cierta importancia; solo don- 
de se ha creado centros distribuidores pueden producir los actos individuales de compartir una economía redistributiva; y solo en presencia de un sistema de formación de precios por el mercado tendrán como consecuencia los actos individuales de intercambio unos precios fluctuantes que integren la economía. En otros casos tales trueques resultaran ineficaces y por tanto, tenderán a no producirse. Caso de que no obstante ocurra, de forma azarosa, se despertara una violenta reacción emocional, como contra los actos indecentes o los actos de traición, puesto que el comportamiento comercial no es un comportamiento emocionalmente indiferente y, por lo tanto, la opinión no lo tolera fuera de los canales aprobados”(Polanyi, 1976:163).

Reciprocidad, redistribución e intercambio son formas modélicas en las que se expresa la institucionalización de la economía en la sociedad, en tanto manifiestan la interdependencia y la recurrencia de los movimientos económicos en las sociedades. Estas formas, se institucionalizan a partir de los conceptos de unidad y estabilidad, es decir, estructuras de prácticas económicas que se expresan a lo largo del tiempo (unidad) y acciones recurrentes exitosas que decantan en la estabilidad del sistema (estabilidad), que, como lo menciona Polanyi, contienen las expresiones de violencia emocional. La institucionalización de estas formas de integración económica que se pueden dar coetáneamente, se expresan, en una doble dimensión analítica, una de carácter histórico que se desarrolla en el modo como se estructuran las actividades económicas en el largo plazo y otra de carácter político que se manifiesta en la función contingente de determinadas prácticas económicas en la sociedad, como acciones que posibilitan la estabilidad del sistema social.

Lareciprocidad como forma de integración, supone relaciones sociales simétricas entre individuos, de manera que para su institucionalización económica necesita de instituciones facilitadoras de organización simétrica, el ejemplo más conocido son los sistemas simétricos de parentescoo filiación. Cabe señalar, que estas formas de integración se dan en diferentes niveles y sectores de la actividad económica, además son amalgamadas con las otras formas de integración. En una unidad económica de tipo doméstica o familiar, por ejemplo, se pueden dar formas de reciprocidad y redistribución paralelamente, lo que las diferenciará serán las pautas institucionales facilitadoras de las mismas que le darán la esencia de su operatoria. Para el caso de la redistribución la asimetría y para el caso de la reciprocidad la simetría. Sin estas pautas institucionales facilitadoras, estas prácticas no se podrían anclar en el proceso económico concreto.

"La reciprocidad como forma de integración gana fuerza en su capacidad de utilizar tanto la redistribución como intercambio a manera de métodos subordinados. La reciprocidad puede conseguirse gracias a compartir una carga de trabajo de acuerdo a determinadas formas de redistribución, como cuando se cogen las cosas por turno. De manera similar, la reciprocidad se consigue a veces mediante 
intercambios de determinadas equivalencias en beneficio del asociado que esta escaso de alguna clase de necesidades (una institución fundamental de las sociedades orientales antiguas). En las economías sin mercado estas dos formas de integración- la reciprocidad y la redistribución-suelen de hecho presentarse juntas" (Polanyi, 1976:164).

Por otra parte, laredistribución se puede expresar de la siguiente manera:

"La redistribución se consigue dentro de un grupo, en la medida en que la asignación de los bienes se reúna en una mano y tenga lugar en virtud de la costumbre, la ley o una decisión central ad hoc. A veces esto significa una reunión física, acompañada de almacenamiento y redistribución, y otras veces la reunión no es física, sino simplemente apropiativa, es decir, el derecho a disponer de la localización física de los bienes. La redistribución se presenta por muchas razones, en todos los niveles de la civilización, desde la tribu cazadora primitiva hasta los grandes sistemas de almacenamiento de Egipto, Sumeria, Babilonia y Perú. En los grandes países, la diferencia de tierra y clima pueden hacer necesaria la redistribución; en otros casos se debe la relevancia a lo relativo al tiempo como ocurre entre la recolección y el consumo. En el caso de la caza, cualquier otro método de distribución conduce a la desintegración de la horda o banda, puesto que en este caso solo la "división del trabajo" puede asegurar los resultados; la redistribución del poder de compra puede ser valiosa en sí misma, es decir, para los propósitos que exigen los ideales sociales de los modernos estados de bienestar. El principio sigue siendo el mismo: reunir y redistribuir desde un centro” (Polanyi, 1976:165).

Cabe señalar que la redistribución no es una cualidad específica de grandes unidades económicas, tanto comunitarias como societales, también ésta puede darse en unidades de menor tamaño como las unidades domésticas o familiares. Al respecto, Polanyi cita los ejemplos de la "Kraal de África central, la familia patriarcal hebrea, la hacienda griega de la época de Aristóteles, la familia romana, el feudo medieval o la típica gran familia campesina anterior a la comercialización general de los cereales. El principio sigue siendo el mismo: reunir y redistribuir desde un centro" (Polanyi, 1976:165).

Con respecto al intercambio, Polanyi va más allá de una perspectiva que asocie intercambio a mercado autorregulado, en otras palabras, el intercambio, si bien, se da esencialmente en el ámbito del mercado, el mercado no es una institución genérica y adquiere especificidades en sus contextos de realización. Este economista plantea que el intercambio de mercado formadores de precios, es uno entre otras formas de intercambio, en tanto se puede dar intercambios a precios fijos en mercados administrados, donde el intercambiono revestiría formaciones de precios. Al respecto, Polanyi distingue tres maneras que adquiere el intercambio en las sociedades: 
“El movimiento meramente locacional de cambio de lugar entre manos (intercambio operacional); los movimientos aproximativos de intercambio con un índice fijo (intercambio decisional) o con un índice contractual (intercambio integrador) En la medida que se trata del intercambio fijo, el sistema está integrado por factores que fijan ese índice, no mediante el mecanismo de mercado. Incluso los mercados formadores de precios solo son integradores si están vinculados en un sistema que tiende a extender el efecto de los precios a otros mercados distintos de los directamente afectados”(Polanyi, 1976:165).

En efecto, cabe señalar, que estas tres formas de integraciónreciprocidad, redistribución e intercambio, no constituyen etapas del desarrollo económico y social, como tampoco implican un orden temporal progresivo, como se suele interpretar superficialmente. Estas formas o modos de integración, pueden manifestarse paralelamente y en diferentes estadios temporales, en tanto, unas pueden ser más preponderantes en determinados periodos que otras. Estos modos de integración económicos no constituyen, a su vez, un análisis de tendencia estructural ni un modelo de etapas de desarrollo, más bien, son formas singulares en las que se instituye lo económico en la sociedad las cuales han presentado cierta recurrencia e interdependencia en el proceso económico a través del tiempo, por lo tanto no deben ser entendidas como categorías estáticas, tampoco como tendencia generales, sino como formas de integración de lo económico en tiempos y espacios determinados, que adquieren dinámicas precisas en los mismos procesos y en sus instituciones facilitadoras.

El modo de abordar la economía en Polanyi es un modelo opuesto al materialismo histórico, concebido como etapas de desarrollo insostenible en términos históricos. El modo Polanyiano, es un tipo de análisis económico inductivo, empirista, teórico y crítico, sustentado en la historia y la antropología económica. Un análisis económico donde la realidad y el comportamiento económico son los principales insumo desde donde se concibe un análisis de la actividad económica entramado en las instituciones sociales, culturales e ideológicas del comportamiento humano.

\section{Consideraciones Finales}

Por análisis económico, Polanyi entendió el corpus de teorías económicas enseñadas en las universidades tradicionalesdejando el marxismo de lado ya que le parecía una concepción errónea del valor y de los precios. No puso, pues, en duda el carácter científico de ese corpus teórico que es el neomarginalismo contemporáneo. Lo que negó, entonces, fue que esas teorías pudieran aplicarse fuera del contexto institucional e histórico particular de las economías de mercado autorregulado, y que eso, pudiese ser un principio de análisis generalizable a todas las realidades económicas.

Para Polanyi, resulta inútil y absurdo utilizar esas teoríasmarginalistas para interpretar el funcionamiento de economías sin mecanismos de merca- 
do formadores de precios, desde lo cual, se desprende su singularización historicistas, sin descuidar el plano de las categorizaciones generales. Esto lo hace no estartan lejosdelos planteamientos de Carlos Marx, aunque fuese crítico de éste como economista en diversos aspectos, ya que en ambos, la economía es siempre históricamente específica, la producción es producción en ciertas etapas del desarrollo social, la producción la hacen los individuos sociales en la historia y las instituciones sociales le dan posibilidad de existencia.

La crítica alcarácter universal de lo económico como maximización y racionalización, es también, una aportación para el análisis de lasciencias sociales, asimismo, el afán de interdisciplinariedad en el análisis económico. El establecimiento de lo económico como un acto total amalgamado en todas las esferas de la vida social, cuestión que algunos enfoques de las ciencias sociales convencionaleshan obviado, en el afán de la medición de índices numéricos. La crítica a lo netamente económico, como móvil de acción del sujeto económico, a la vez tambiénsocial, es otras de las aristas que se desprenden del pensamiento del economista húngaro.

En el plano político-académico, el pensamiento de Karl Polanyi:

“Nos permite seguir defendiendo (epistemológica y empíricamente) que otras economías y sociedades alternativas son posibles, que otros procesos de estructuración de prácticas sociales permitirán retomar apuestas desmercantilizadoras de inclusión social, pero sin que podamos olvidar que requerirá una movilización ingente de recursos de socialización y de inversión performativa de esos valores y prácticas sociales alternativos, en los que siguiendo a Polanyi, habrá que garantizar las libertades políticas y democráticas”.(Lahera, 2013:561)

Todos estos elementos que hemos señalado a lo largo del presente análisis del pensamiento económico de Karl Polanyi, expresan una visión del trabajo académicomás allá de los reduccionismos economicistas, ya que en la lógica de Polanyi, lo económico está inserto en la sociedad, amalgamado con la cultura y lasestructuras de largo plazo. En efecto, el pensamiento económico delautor,es también una aportacióncritica alanálisis complejo del campo de los hechos económicos, a su vez, una contribución política para seguir sosteniendo que otra sociedades y economías son posibles. 
Polis, Revista Latinoamericana, Volumen 15, $N^{\circ}$ 45, 2016

\section{Notas}

${ }^{1}$ En estricto rigor, Polanyi no era un marxista si creía para este periodo en un tipo de economía socializante y planificada, era anti-liberal muy cercano a las propuestas del esquema teórico del historicismo alemán. Era un socialista porque creía en un tipo de sociedad diferente a la de mercado autoregulado, pero no era un ortodoxo militante socialista, que para el periodo consistía en adscribirse al marxismo y posteriormente al marxismo leninismo. Los posteriores trabajos de Polanyi la "Gran transformación" (1944), “Comercio y mercados en los imperios antiguos(1957)”, desarrollará criticas importantes al materialismo histórico y a su teoría de los modos de producción

${ }^{2}$ Para Polanyi, la preponderancia de las economías de mercado autorregulado como forma de integración en las sociedades industrializadas a partir del Siglo XIX, no es el resultado natural del comportamiento económico, sino una excepcionalidad histórica, que ha dependido esencialmente de la regulación política de un interés sectorial. Para el autor los estados son más eficientes a la hora de impulsar el comercio de mercado, que la empresa privada. De esta manera, la formación de un sistema mercantil que integre a las economías de mercados nacionales en una lógica de formaciones de precios internacionales y estructuras institucionales tendientes a aunar criterios entorno a un mercado global, es una auténtica invención en la historia de la humanidad 


\section{Bibliografía}

Álvarez-Uria, F. (2014),“Karl Polanyi y sus contemporáneos: Sobre la subordinacioìn de los mercados a los valores de la civilizacioìn y de la libertad”, Encrucijadas-Revista Crítica de Ciencias Sociales, Madrid.

Godelier, M. (1976), Antropología y economía, Editorial Anagrama, Barcelona.

Hobsbawm, E. (1998), "Historiadores y economistas”. Sobre la Historia, Editorial Crítica, Barcelona.

Lahera, A. (2013), "Nuestra hegemónica mentalidad de mercado. Actualidad y límites (democráticos) del pensamiento político de Karl Polanyi”, en Sociología Histórica, Madrid.

Polanyi, K. (2003), La Gran transformación, Fondo de Cultura Económica, Ciudad de México.

Polanyi, K., Alier, J. M., Pearson, H. W., Arensberg, C. M., \& Nicolás, A. (1976), Comercio y mercado en los imperios antiguos, Editorial Labor, Barcelona.

Rendueles, C. (2004), "Karl Polanyi o la humildad de las Ciencias Sociales", Nexo. Revista de Filosofía, 2.

Subirats, J. (2014), “Acerca del renovado interés por Karl Polanyi”. Cuadernos EBAPE. BR, 12(2), Rio de Janeiro.

Recibido: 14.01 .15

Aceptado: 21.09.15 